\title{
Evaluation of target area concentration (TAC) programme in Malaysia's integrated cattle and oil palm farming
}

\begin{abstract}
Malaysia's beef production falls under three types of production methods: traditional system, intensive system of cattle feedlots, and integrated farming system. The objective of this study is to investigate and evaluate the effectiveness of the target area concentration (TAC) programme conducted by the Department of Veterinary Services (DVS) that focuses on the integrated farming system between cattle and oil palm plantation. This study intends to identify the programme's achievement through context, input, process, and product (CIPP) analysis. The analysis reveals that the real needs of the programme context are being met by TAC; the provision meets the needs of inputs but there are some constraints; the implementation of the TAC programme is running well and receives good cooperation from farmers, but there are some constraints; and there is a positive impact of the programme in terms of production, income, employment, changes in knowledge, skill, attitude, and practice. Overall, the TAC programme has thus far achieved its objectives, but it needs some improvements.
\end{abstract}

Keyword: Cattle farming; Oil palm; Integrated farming; Target area concentration (TAC); Veterinary extension services 